\title{
Physicians Interrupting Patients
}

\author{
Kari A. Phillips, $M D^{7}$, Naykky Singh Ospina, MD, MSC ${ }^{2}$, and Victor Montori, MD, MSC ${ }^{3}$
}

'Department of Pediatric and Adolescent Medicine, Mayo Clinic, Rochester, MN, USA; ${ }^{2}$ Division of Endocrinology, Department of Medicine, University of Florida, Gainesville, FL, USA; ${ }^{3}$ Knowledge and Evaluation Research Unit, Division of Endocrinology, Diabetes, Metabolism and Nutrition, Department of Medicine, Mayo Clinic, Rochester, MN, USA.

J Gen Intern Med 34(10): 1963

DOI: $10.1007 / \mathrm{s} 11606-019-05141-0$

(c) Society of General Internal Medicine 2019

$\mathrm{D}$ r. Ortega highlights an incredibly important, often understudied but common aspect of current medical practice - the nuance of multi-lingual medical encounters. Medical encounters with discordant languages between the clinician and patient bring with them numerous challenges, not the least of which is time. ${ }^{1}$ These visits likely require at least twice as much time, which often is not accounted for when they are scheduled. This makes time constraints even more pressing, and increase the risk for patient interruption, clinicians that feel pressured by time and inadequate communication and care. ${ }^{1,2}$ Furthermore, these visits rely on expression and perception of empathy through a third party (the interpreter). ${ }^{3}$

Another valuable point is the underrepresentation of nonEnglish-speaking participants in clinical trials, as was the case in our study. This is likely a result of barriers that span from limited opportunity to participate in research for these patients (e.g., excluded or not asked to enroll) to limited trust in the research team (e.g., limited information about the study in their language). ${ }^{4}$

Caring for patients with limited proficiency in the language spoken by their clinical team is challenging. Clinicians should be aware of the barriers these patients face when seeking care and make every effort to assure they provide adequate care. However, until significant changes to our current medical system are made, these patients would continue to be vulnerable. We whole-heartedly agree future communication research should include and/or focus specifically on these increasingly common, but nonetheless challenging situations.

Corresponding Author: Victor Montori, MD, MSC; Knowledge and Evaluation Research Unit, Division of Endocrinology, Diabetes, Metabolism and Nutrition, Department of Medicine Mayo Clinic, Rochester, MN, USA (e-mail: montori.victor@mayo.edu).

\section{Compliance with Ethical Standards:}

Conflict of Interest: The authors declare that they do not have a conflict of interest.

\section{REFERENCES}

1. Parsons JA, Baker NA, Smith-Gorvie T, Hudak PL. To 'Get by' or 'get help'? A qualitative study of physicians' challenges and dilemmas when patients have limited English proficiency. BMJ Open. 2014;4(6):e004613.

2. Wilson E, Chen AH, Grumbach $\mathbf{K}$, Wang $\mathbf{F}$, Fernandez A. Effects of limited English proficiency and physician language on health care comprehension. J Gen Intern Med. 2005;20(9):800-806.

3. White J, Plompen T, Osadnik C, Tao L, Micallef $\mathbf{E}$, Haines $\mathbf{T}$. The experience of interpreter access and language discordant clinical encounters in Australian health care: a mixed methods exploration. Int J Equity Health. 2018;17(1): 151

4. Ford JG, Howerton MW, Lai GY, et al. Barriers to recruiting underrepresented populations to cancer clinical trials: a systematic review. Cancer. 2008; $112(2): 228-242$

Publisher's Note Springer Nature remains neutral with regard to jurisdictional claims in published maps and institutional affiliations. 